\title{
The Effect of Gas Smelling among Fuel Stations Employees in Qassim Region
}

\author{
Raseel Yosef Al Fawzan, Amal Hussain Mohamed Ali* \\ Department of Medical Laboratories, College of Applied Medical Sciences, Qassim University, Buraydah, KSA \\ Email: raseel1419@gmail.com, *ama.ali@qu.edu.sa
}

How to cite this paper: Al Fawzan, R.Y. and Ali, A.H.M. (2021) The Effect of Gas Smelling among Fuel Stations Employees in Qassim Region. Journal of Biosciences and Medicines, 9, 52-62.

https://doi.org/10.4236/jbm.2021.92006

Received: October 22, 2020

Accepted: February 20, 2021

Published: February 23, 2021

Copyright $\odot 2021$ by author(s) and Scientific Research Publishing Inc. This work is licensed under the Creative Commons Attribution International License (CC BY 4.0).

http://creativecommons.org/licenses/by/4.0/

(c) (i) Open Access

\begin{abstract}
Benzene is a carcinogenic compound used in industrial manufacturing. Benzene exposure is associated with a multiplicity of clinical conditions ranging from hematologic diseases to chronic lung disorders. Respiratory system is affected more than the other system because the benzene is highly volatile and inhaled deeply into respiratory airway reaching the alveoli where gas exchange takes place. This study aims to show the effect of benzene on respiratory system of fuel station employees and its role in causing respiratory problems. The design of the study is an experimental study to evaluate the effect of benzene inhalation on the lung tissue by detecting cytological change among Fuel stations employees in Qassim region. The sputum sample was obtained from male stations employees in Qassim region and stained with Papanicolaou stain. The fuel station employees were suffering from dyspnea, nasal irritation and sore throat. In total 15 sputum samples collected are subdivided into three groups: group number one is those not exposed to benzene; the second group is exposed for 2 - 4 years. However, group number three is exposed for more than 4 years. Long-term exposure to benzene leads to cytological change and reduces immunity that is indicated by the present of neutrophil cells (pus) and other inflammatory features.
\end{abstract}

\section{Keywords}

Benzene, Respiratory System, Cytological Change, Fuel Station Employees

\section{Introduction}

Benzene is a carcinogenic compound used in industrial manufacturing and a common environmental pollutant mostly derived from vehicle emissions and cigarette smoke. Benzene exposure is associated with a multiplicity of clinical conditions ranging from hematologic diseases to chronic lung disorders [1]. 
Benzene exposure may affect many systems of the body exclusively respiratory system which affected more than other systems because the benzene is highly volatile and inhaled deeply into respiratory airway reaching the alveoli where gas exchange takes place [2]. Respiratory problem consequence has been reported in humans after acute exposure to benzene vapors [3]. This study is to show the complicated benzene inhalation on respiratory cells among fuel station employees. Fuel stations are important source of pollution of air, in which there are complex combinations of different petroleum products and vapors. Petrol vapors consist of a complex mixture of hydrocarbons. About $95 \%$ are aliphatic and cyclic compounds, $2 \%$ are aromatic compounds, and benzene is about $1 \%-5 \%$ [4].

Benzene is readily absorbed following inhalation or oral exposure. Although benzene is also easily absorbed from the skin, the absorbed benzene is immediately distributed throughout the body and tends to accumulate in fatty tissues. The liver has a critical function in benzene metabolism, which results in the production of different reactive metabolites. At low levels of exposure, benzene is rapidly metabolized and excreted mostly as conjugated urinary metabolites. At higher levels of exposure, metabolic pathways appear to become saturated and a large amount of an absorbed dose of benzene is excreted in exhaled air [5]. Data on the distribution of benzene in humans come mainly from case studies. The data suggest that benzene is distributed throughout the body following absorption into blood. As the benzene is lipophilic, a high distribution to fatty tissue might be expected. Effect of benzene inhalation reflects in the biological fluids of humans [6].

Employees in fuel stations suffer continuous and constant exposure to evaporations and car exhaust and dust from the passing vehicles' exhausts on the streets. All these reasons make the employees at a high chance to develop complications of respiratory airways and lung tissue [7]. Benzene constitutes 1\% $2 \%$ of most blends of gasoline and is released as a vapor from vehicular emissions. Since benzene is a constituent of auto exhaust and fuel evaporation, people who spend more time in cars or in areas of heavy traffic have increased personal exposure to benzene. Assuming an average benzene concentration of 40 $\mathrm{mg} / \mathrm{m}^{3}(12.5 \mathrm{ppb})$ for a moving automobile and an exposure duration of 1 hour/day, the calculated intake for driving or riding in an automobile is 40 $\mathrm{mg} /$ day [3]. The effect of the exposure to benzene will different according to duration of exposure and amount of inhaled benzene from $10.000-20.000 \mathrm{ppm}$ for short time. Although benzene influences the physiology of different systems of the body, respiratory system is particularly highly affected because of being the main route of exposure by inhalation [8].

Benzene is inhaled deeply into the lungs through the nasopharyngeal, trachea, bronchi, and bronchioles reaching to the alveoli where gas exchange takes place. It leads to carcinogenic effects of the epithelial cells lining the respiratory system including terminal bronchioles, respiratory bronchioles and alveoli [9]. Sputum 
cytology has been successful in many cases in the diagnosis of bronchogenic carcinoma [10]. Usually a small amount of the sputum sample is processed and examined under microscope for the presence of atypical cells. There are different studies of sputum cytology showing the average sensitivity of $65 \%$, with a wide range of $22 \%-98 \%$. This broad variability depends on the location of the lesion [11]. Therefore, the aim of this study is to determine the effect of Benzene products on the respiratory cell among fuel stations' employees in Qassim City by using cytological methods.

\section{Methodology}

The design of the study is an experimental study to evaluate the effect of Benzene inhalation on the lung tissue by detecting cytological change among fuel stations' employees in Qassim region. The sputum sample will be obtained from male stations' workers in Qassim region and stained with Papanicolaou stain. The sample size is 15 . The sputum obtained from the employees in the morning, without use of mouthwash is due to negative impact on final result then the specimen spreading on the microscopic glass slides and fixed with alcohol, stained with Papanicolaou stain and examined under the microscope.

\subsection{Papanicolaou Stain (PAP Stain)}

It is the most important stain utilized in the practice of Cytopathology. It is a polychromatic stain containing multiple dyes to differentially stain various components of the cells. This technique was developed by George Papanicolaou, the father of cytopathology. This method is used to differentiate cells in the smear preparation of various gynecological specimens (pap smears), materials containing exfoliative cells and material from fine needle aspiration. Papanicolaou stain includes both acidic and basic dyes. Acidic dye stains the basic components of the cell and basic dye stains the acidic components of the cell. The polychromatic

PAP stain involves five dyes in three solutions.

1) Hematoxylin: Natural dye hematoxylin is the nuclear stain which stains cell nuclei blue. It has affinity for chromatin, attaching to sulphate groups on the D.N.A. molecule. Harris' hematoxylin is the commonest cytologically although Gills' hematoxylin and Hematoxylin $\mathrm{S}$ can be used.

2) Orange green 6: This is the first acidic counterstain (cytoplasmic stain) which stains matured and keratinized cells. The target structures are staine $\mathrm{d}$ orange in different intensities.

3) Eosin azure: This is the second counterstain which is a polychrome mixture of eosin Y, light green SF and Bismarck brown. Eosin $\mathrm{Y}$ gives a pink colour to cytoplasm of mature squamous cells, nucleoli, cilia and red blood cells. Staining solutions commonly used in cytology are EA 31 and EA 50, while EA 65.

4) Light green SF stains blue to cytoplasm of metabolically active cells like parabasal squamous cells, intermediate squamous cells and columnar cells. 


\subsection{Procedure of Progressive Papanicolaou Staining Method}

In the progressive method, the nucleus is stained with hematoxylin to a intensity desired. The intensity of the nuclear staining is controlled by the immersion of the slide into a bluing agent. Most commonly used bluing agent is Scott's tap water ( $\mathrm{pH}$ 8.02).

\begin{tabular}{|c|c|c|}
\hline Step & Reagent & Time \\
\hline 1. & 95\% Alcohol (Fixation) & 15 - 30 minutes \\
\hline 2. & $60 \%$ Alcohol & 2 minutes \\
\hline 3. & Distilled Water & 5 dips \\
\hline 4. & Distilled Water & 5 dips \\
\hline 5. & Hematoxylin stain & 3 minutes \\
\hline 6. & Distilled Water & 3 minutes \\
\hline 7. & $60 \%$ Alcohol & 2 minutes \\
\hline 8. & 80\% Alcohol & 2 minutes \\
\hline 9. & 95\% Alcohol & 2 minutes \\
\hline 10. & Orange G Stain & 3 minutes \\
\hline 11. & 95\% ALcohol & 2 minutes \\
\hline 12. & 95\% Alcohol & 2 minutes \\
\hline 13. & Eosin Azure Stain & 3 minutes \\
\hline 14. & 95\% Alcohol & 2 minutes \\
\hline 15. & 95\% Alcohol & 2 minutes \\
\hline 16. & 95\% Alcohol & 2 minutes \\
\hline 17. & 95\% Alcohol & 2 minutes \\
\hline 18. & Absolute Alcohol & 2 minutes \\
\hline 19. & Absolute Alcohol & 2 minutes \\
\hline 20. & Absolute Alcohol & 2 minutes \\
\hline 21. & Absolute Alcohol + Xylene (1:1) & 2 minutes \\
\hline 22. & Xylene & 2 minutes \\
\hline 23. & Xylene & 2 minutes \\
\hline 24. & Xylene & Till clear \\
\hline 25. & Mount in D.P.X & \\
\hline
\end{tabular}

\section{Result}

The Bartlett score measures the quality of sputum specimens testing. The score is derived from a microscopic exam of sputum specimens that looks at:

1) the number of neutrophils per low power field;

2) the presence of mucus strands;

3) the number of squamous epithelial cells per low power field;

4) segmented neutrophils and mucus strands may be indicative of inflammation; 
5) high quality sputum specimens with high numbers of epithelial cells are not indicative of inflammation and might indicate contamination with saliva.

A score of 1, 2, or 3 indicates active inflammation. A score of 0 or less indicates a lack of inflammation or contamination with saliva.

General symptoms between most employees are dyspnea, nasal irritation and sore throat.

Fifteen sputum samples collected and subdivided into three groups:

1) Group number one:

This group include normal human didn't exposure to benzene as control, main cell found in the section is squamous epithelial cell show well-differentiated cytoplasm. The cytoplasmic is eosinophilia. Nuclei are small, with a very fine chromatin pattern (Figure 1). Person working for one year exposing to benzene inhalation also shows squamous epithelial cell well-differentiated cytoplasm. The cytoplasmic staining can range from basophilic (blue) to eosinophilia (red). The nuclei are small, with a very fine, chromatin pattern. The section includes epithelial cell with numerous bacteria have adhesins that promote sticking to the surfaces, hence they tend due to adhering on the surfaces leading to appearance of granularity with indistinct or stippled border it seems like clue cells., with excessive mucous secretion (Figure 2).

2) Second group:

Employee works for 2 years exposing to benzene, the sample of him shows squamous epithelial cell with pyknotic nucleus indicates degeneration with mucus secretion. Other cells seem like clue cells which are fuzzy appearance cell without sharp edges under a microscope. Clue cells change to this fuzzy look when they are coated with bacteria. In this sample the present of neutrophil and excessive mucous secretion indicate inflammation (Figure 3).

Employee working for 3 years exposing to benzene shows squamous epithelial with hazy cytoplasm and clear vacuolation with slightly increase in nucleolus size and condensation of chromatin in the nuclear border on one side leaving empty area on nucleus (anomaly stain) and amount of neutrophil distribution throw the section general feature is anomaly of Stain with inflammation appearance (Figure $4)$.

Employee works for 4 years exposing to benzene, the sample of this person shows degenerative squamous cell (karyolysis: squamous cell without nucleus) with increase of neutrophil. It is sign of inflammation. The section appears very clear from mucous secretion which indicates dryness (Figure 5).

Other volunteer sample shows intermediate cell with small amount of hazy cytoplasm and vacillation, the percentage of bacteria increasing and cover the epithelial cell (clue cell) with small amount of mucus secretion (Figure 6).

3) Third group:

Employee exposed to benzene more than 4 years suffers from dyspnea, nasal irritation and sore throat. The sample of this participate show increase of amount of bacteria inside and outside the squamous epithelial cell suggest immune complication. With excessive mucous secretion and Increase the number of neutro- 
phils which indicate inflammation. We found also large squamous epithelial cell with hazy cytoplasm (Figure 7).

Sample eight shows also increasing amount of degenerative cell (Karyolysis) large squamous cell without nucleus, sometimes with eccentric nucleolus.

The excessive mucus secretion with turbidity in background indicated inflammation number of neutrophils increase with bulk of bacteria condensation (Figure 8).

\section{1) Group one-Normal Sample:}

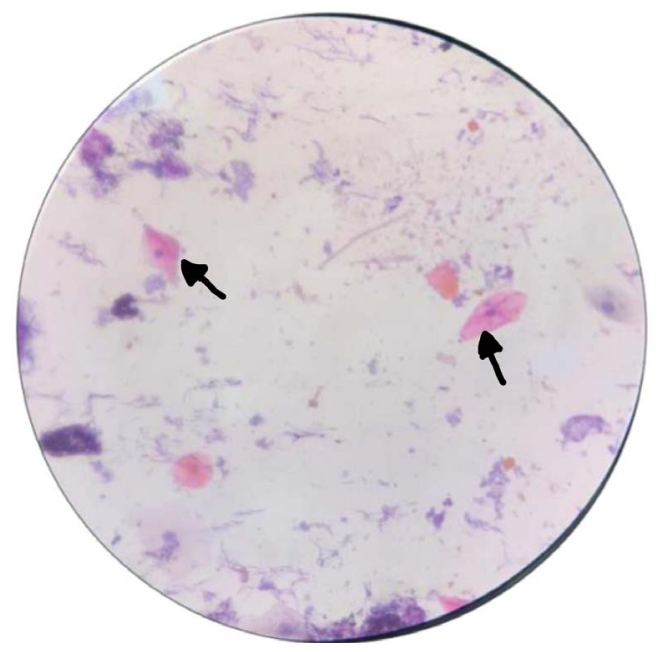

Figure 1. Sample one. Black arrow: squamous epithelial cells show well-differentiated cytoplasm. Thin polygonal shape with sharp corners. The cytoplasmic is eosinophilia (red). The nuclei are small, with a very fine chromatin pattern.

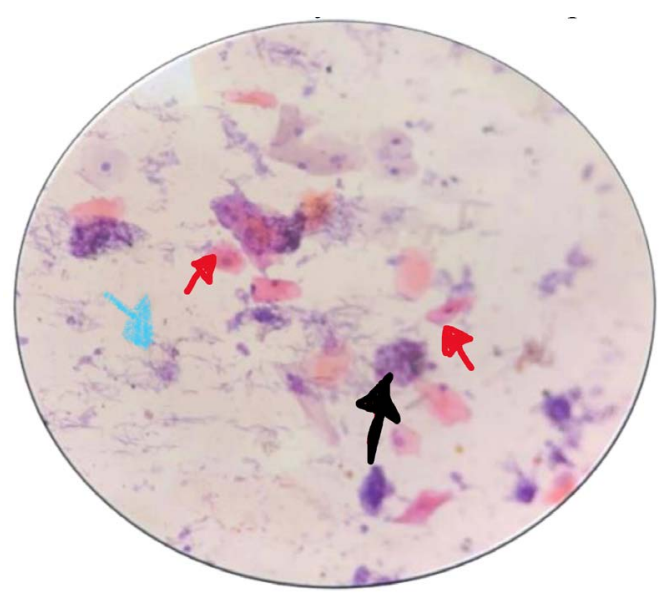

Figure 2. Sample two. No effect or cytological change. Employee works for one year exposing to benzene: 1) Red arrow: squamous epithelial cells show mature, well-differentiated cytoplasm. The thin polygonal shape with sharp corners. The cytoplasmic staining can range from basophilic (blue) to eosinophilia (red). The nuclei are small, with a very fine, chromatin pattern. 2) Black arrow: normal squamous epithelial cells have distinct cell margins and lack granularity. Numerous bacteria have adhesins that promote sticking to the surfaces, hence they tend due to adhering on the surfaces leading to appearance of granularity with indistinct or stippled border it seems like clue cells. 3) Blue arrow: excessive thread mucous secretion. 


\section{2) Group two:}

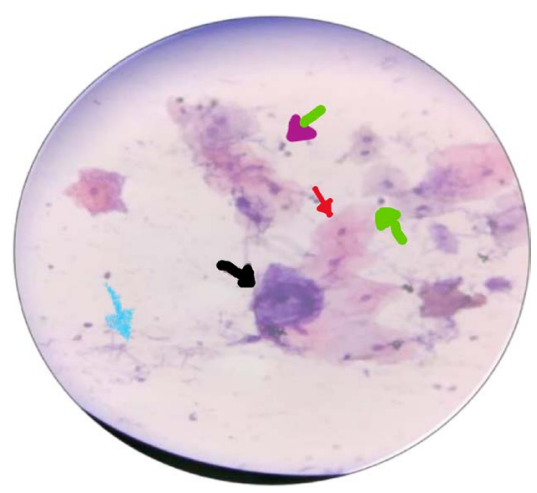

Figure 3. Sample three. Employee works for 2 years exposing to benzene: 1) Red arrow: squamous epithelial cell with pyknotic nucleus indicates degeneration with mucus secretion. 2) Black arrow: cells seem like clue cells which are certain cells that appear fuzzy without sharp edges under a microscope. Clue cells change to this fuzzy look when they are coated with bacteria. 3) Green arrow: pus cell (neutrophil). 4) Blue arrow: thread mucous secretion.

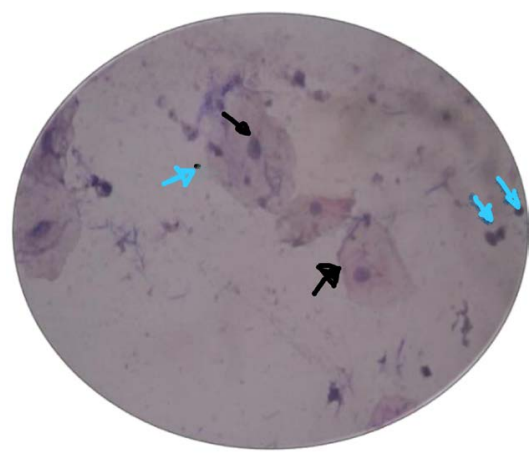

Figure 4. Sample four. Employee works for 3 years exposing to benzene: 1) Black arrow: Squamous epithelial with hazy cytoplasm and clear vacuolation. 2) Slightly increase in nucleolus size with condensation of chromatin in the nuclear border on one side, leaving empty area on nucleus, anomaly of stain. 3) Blue arrow: pus cell (neutrophil). 4) General feature: anomaly stain.

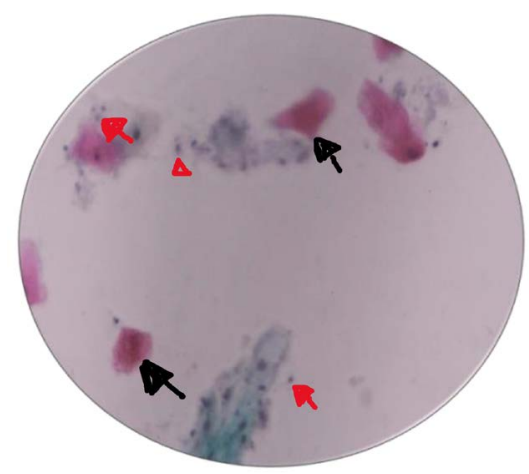

Figure 5. Sample five. Employee works for 4 years exposing to benzene: 1) Black arrow: degenerative of squamous cell (karyolysis:squamous cell without nucleus). 2) Red arrow: increase amount of pus cell (neutrophil). $\rightarrow$ Indicate inflammation. 3) Decrease mucus secretion. Indicate dryness. 


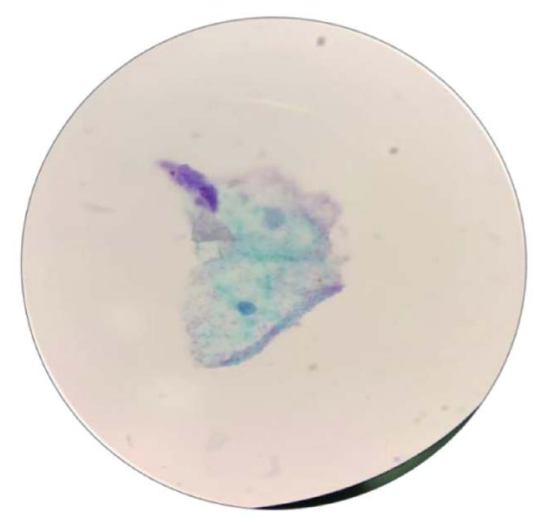

Figure 6. Sample six. Employee works for 4 years exposing to benzene: 1) Intermediate cell shows small amount of hazy cytoplasm and vacillation, the percentage of bacteria increasing and cover the epithelial cell. 2) Clear section indicated low mucus secretion.

\section{3) Group three "more than 4 years":}

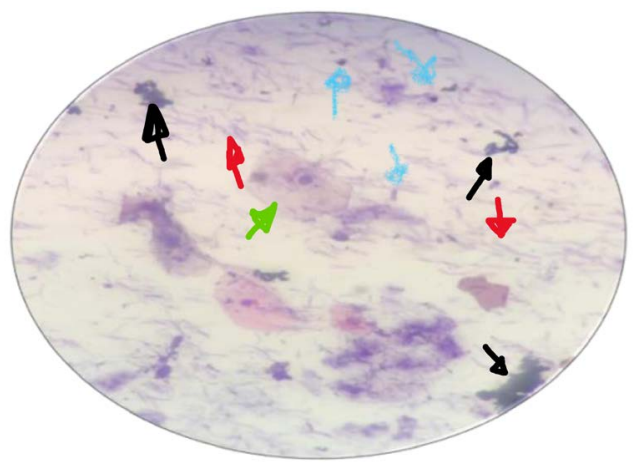

Figure 7. Sample seven. 1) Black arrow: increase of amount of bacteria inside and outside the squamous epithelial cell suggests immune complication. 2) Red arrow: excessive mucous secretion indicated inflammation. 3) Blue arrow: increase number of neutrophils indicated inflammation. 4) Green arrow: large size of squamous epithelial cell with hazy cytoplasm.

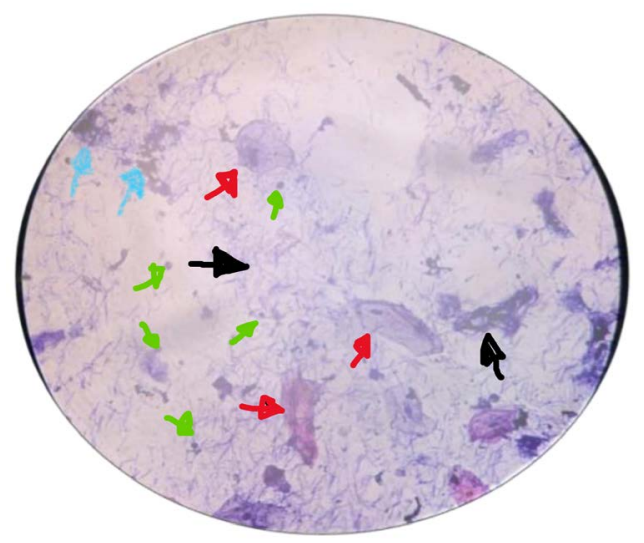

Figure 8. Sample eight. 1) Red arrow: appearance of degenerative cell (karyolysis) large squamous cell without nucleus, some time with eccentric nucleolus; 2) Black arrow: excessive mucus secretion, turbidity in background indicated inflammtion; 3) Green arrow: increase number of neutrophils indicated inflammation; 4) Blue arrow: increase of amount of bacteria condensation. 


\section{Discussion}

Rennard's study in 1990 [12] showed increase in the incidence and sensitivity of respiratory cell to long-term benzene exposure. This result is similar to our result. Bender, Ostenson, Wang and Beavo at 2004 [13] said the function of epithelial cells that cover airway are acting as a physical barrier and secreting excessive mucus that traps inhaled particles which is important to host defense system, our result finding from investigation of group number 2 and 3 with long year exposure to benzene inhalation show evidence of excessive mucus secretion. Triggiani et al., in 2011 [1] suggest hydroquinone and benzoquinone have inhibitory effects on basophils and mast cells by reduced functions of basophils and mast cells leading to a global impairment of innate immunity which may be responsible for the enhanced susceptibility to infections with chronic exposed to benzene.

Moreover, in experimental study done by Rosenthal and Snyder in 1985 [14] on mice by pre-exposure to benzene at $30 \mathrm{ppm}$ for 5 - 12 days showing increase in bacterial amount in day 4 of infection. Our result shows $50 \%$ of bacterial infection increase in different samples.

Additionally, we agree with Yin et al., in 1987 [15] they found similar Symptoms like mucous membrane irritation in $80 \%$ and dyspnea was noted in $67 \%$ of the employees which exposures to $>60 \mathrm{ppm}$ for up to 3 weeks. Nasal irritation and sore throat were reported by male and female employees exposed to 33 and 59 ppm benzene, respectively for more than 1 year. We found all these symptoms in the participant of our study like mucous membrane irritation, dyspnea, nasal irritation and sore throat.

\section{Conclusion}

Long-term exposure to benzene leads to cytological change in lung and affects the immunity and cellular change.

\section{Recommendation}

The fuel station employees should not exceed two years of work. Also, they should do cytological follow-up every year to determine any change in lung tissue. Moreover, we need more studies with an increased sample size to discuss these problems.

\section{Acknowledgements}

First, I would like to thank my dear doctor, Dr. Amal Hussain for her trust in me and for all the support that she provided to me with the effort and work environment. Second, I would like to extend my full gratitude to my dear father, who provided assistance to me, while my research relied on gas station workers. Also, I would like to thank my friends who did not leave me for a moment and Siyad Shareef from India. Finally for myself not to give in and conduct it despite all the circumstances. 


\section{Conflicts of Interest}

The authors declare that there are no conflicts of interest.

\section{References}

[1] Triggiani, M., Loffredo, S., Granata, F.I., Staiano, R. and Marone, G. (2011) Modulation of Mast Cell and Basophil Functions by Benzene Metabolites. Current Pharmaceutical Design, 17, 3830-3835. https://doi.org/10.2174/138161211798357863

[2] Shwaish, Z., Kawaz, W. and Shwaish, T. (2017) Pattern of Obesity and Sociodemographic Characteristics for Nutrition CLINIC Clients in Basra, Iraq. International Journal of Advanced Research, 5, 920-926. http://dx.doi.org/10.21474/IJAR01/5605

[3] Winek, C., Collom, W. and Wecht, C. (1967) Fatal Benzene Exposure by Glue-Sniffing. The Lancet, 289, 683. https://doi.org/10.1016/S0140-6736(67)92578-0

[4] Tyagi, D. and Devanshi, U.D. (2012) Pulmonary Function Test in Petrol Pump Workers of Ahmedabad. International Journal of Scientific Research, 2, 380-381. https://doi.org/10.15373/22778179/JULY2013/129

[5] Medinsky, M., Sabourin, P., Lucier, G., Birnbaum, L. and Henderson, R.A. (1989) Physiological Model for Simulation of Benzene Metabolism by Rats and Mice. Toxicology and Applied Pharmacology, 99, 193-206. https://doi.org/10.1016/0041-008X(89)90002-1

[6] Pekari, K., Vainiotalo, S., Heikkila, P., Palotie, A., Luotamo, M. and Riihimaki, V. (1992) Biological Monitoring of Occupational Exposure to Low Levels of Benzene. Scandinavian Journal of Work, Environment \& Health, 18, 317-322.

https://doi.org/10.5271/sjweh.1570

[7] Uzma, N., Khaja Mohinuddin Salar, B., Kumar, B., Aziz, N., David, M. and Reddy, V. (2008) Impact of Organic Solvents and Environmental Pollutants on the Physiological Function in Petrol Filling Workers. International Journal of Environmental Research and Public Health, 5, 139-146. https://doi.org/10.3390/ijerph5030139

[8] Sharma, M. and Nanorobotics, G.R. (2016) The Future of Medicines. Research in Pharmacy and Health Sciences, 2, 51-56. https://doi.org/10.32463/rphs.2016.v02i01.10

[9] Weaver, C., Liu, S., Lu, J. and Lin, B. (2006) The Effects of Benzene Exposure on Apoptosis in Epithelial Lung Cells: Localization by Terminal Deoxynucleotidyl Transferase-Mediated dUTP-Biotin Nick End Labeling (TUNEL) and the Immunocytochemical Localization of Apoptosis-Related Gene Products. Cell Biology and Toxicology, 23, 201-220. https://doi.org/10.1007/s10565-006-0165-2

[10] Kietzmann, M. (2000) Principles of Environmental Toxicology, I.C. Shaw, J. Chadwick, Taylor \& Francis, Ltd., London, 1998, XIII +216 pp. Toxicon, 38, 470. https://doi.org/10.1016/S0041-0101(99)00097-5

[11] Schumann, G., Roby, T., Swan, G. and Sorensen, K. (1989) Quantitative Sputum Cytologic Findings in 109 Nonsmokers. American Review of Respiratory Disease, 139, 601-603. https://doi.org/10.1164/ajrccm/139.3.601

[12] Rennard, S.I. (1990) Bronchoalveolar Lavage in the Diagnosis of Cancer. Lung, 168, 1035-1040. https://doi.org/10.1007/BF02718241

[13] Bender, A., Ostenson, C., Wang, E. and Beavo, J. (2004) Selective Up-Regulation of Pdeib2 upon Monocyte-to-Macrophage Differentiation. Proceedings of the National 
Academy of Sciences of the United States of America, 102, 497-502.

https://doi.org/10.1073/pnas.0408535102

[14] Rosenthal, G. and Snyder, C. (1985) Modulation of the Immune Response to Listeria monocytogenes by Benzene Inhalation. Toxicology and Applied Pharmacology, 80, 502-510. https://doi.org/10.1016/0041-008X(85)90395-3

[15] Yin, S.N., Li, G.L., Hu, Y.T., Zhang, X.M., Jin, C., Inoue, O., et al. (1987) Symptoms and Signs of Workers Exposed to Benzene, Toluene or the Combination. Industrial Health, 25, 113-130. https://doi.org/10.2486/indhealth.25.113 